\title{
Factors Associated with Low Self-Esteem in Children with Overweight*
}

\author{
Yngvild Sørebø Danielsen ${ }^{a} \quad$ Kjell Morten Stormark ${ }^{b} \quad$ Inger Hilde Nordhus $^{c}$ \\ Magne Mæhle ${ }^{b} \quad$ Liv Sand $^{b} \quad$ Belinda Ekornås ${ }^{b} \quad$ Ståle Pallesen ${ }^{a}$ \\ ${ }^{a}$ Department of Psychosocial Science, University of Bergen, ${ }^{b}$ Centre for Child and Adolescent \\ Mental Health, Uni Research, 'Department of Clinical Psychology, University of Bergen, Bergen, \\ Norway
}

\section{Key Words}

Self-esteem • Overweight · Obesity $\cdot$ Disturbed eating $\cdot$ Bullying

\begin{abstract}
Objective: Low self-esteem is one of the main psychosocial factors related to childhood overweight. Yet not all overweight children are affected. Little is known about what characterises the group of overweight children with the lowest self-esteem. Our aim was to identify factors related to low domain-specific self-esteem in children with overweight/obesity. Methods: Children (aged 10-13; $N=5,185$ ) and parents from a large population-based sample completed the Eating Disturbance Scale, the Self-Perception Profile for Children, and questions about bullying and socio-economic status (SES). Parents reported the child's weight and height. 545 children with overweight/obesity were identified in the overall sample and selected for the current analyses. Self-esteem scores from this group were compared to scores from children with normal weight. Factors examined in relation to self-esteem in children with overweight/obesity were: age, gender, SES, disturbed eating, bullying, parents' evaluation of weight status and degree of overweight. Results: Children with overweight scored significantly lower than normal-weight children on all self-esteem domains. Athletic competence and physical appearance were most impaired. Disturbed eating and bullying were related to low physical appearance as well as scholastic, social and athletic self-esteem. Being female, a pre-teen, having a higher BMI and being evaluated as overweight by parents were associated with lower satisfaction with physical appearance. Conclusions: Disturbed eating and bullying are significantly related to low self-esteem in the overweight group.
\end{abstract}

Copyright (c) 2012 S. Karger GmbH, Freiburg

*The study is part of a large longitudinal population-based study in Norway the Bergen Child Study (BCS). The sampling and methods of the BCS are first described in: Heiervang E, Stormark KM, Lundervold AJ, Heimann M, Goodman R, Posserud MB, et al: Psychiatric disorders in Norwegian 8- to 10-year-olds: an epidemiological survey of prevalence, risk factors, and service use. J Am Acad Child Adolesc Psychiatry 2007;46:438-447. 
Danielsen et al.: Factors Associated with Low Self-Esteem in Children with Overweight

\section{Introduction}

Knowledge about the prevalence of self-esteem problems in children with overweight or obesity is growing. However, less is known about which self-esteem domains are particularly impaired in children with overweight/obesity and what characterises the sub-group of children with overweight/obesity that demonstrates lower self-esteem. This topic may be of particular interest in relation to planning prevention, assessment and treatment strategies for children with overweight/obesity. With regard to the development of intervention strategies that promote self-esteem in overweight children, information about which selfesteem domains are particularly important to target and about related factors that might deserve focus are useful.

Most population-based studies and studies on non-treatment-seeking children with overweight and obesity find body image to be impaired, but global self-esteem to be within the normal range [1-4]. However, there seem to be sub-groups of children with overweight/ obesity who are particularly at risk of low self-esteem [5,6]. Identifying factors that are associated with low self-esteem in children with overweight/obesity could enhance our knowledge about a group of children that suffer psychologically.

Most previous studies on self-esteem in children have focused on global measures of self-esteem. More recently, however, emphasis has been placed on multi-dimensional measures, highlighting different domains of self-esteem [7]. The different domains of selfesteem are not necessarily related to global self-esteem [8]. Theories of self-esteem often differentiate between global and specific self-esteem $[9,10]$. While global self-esteem mainly is related to general psychological well-being, specific self-esteem is more important for behaviours on different arenas. The influence of specific self-esteem on global self-esteem will depend on how highly that specific area is valued by the person [9]. Self-esteem is also considered to be influenced by the discrepancy between the ideals and the accomplishments of a child within a specific area as well as upon perceived emotional support from parents and peers $[9,10]$. Several studies indicate that some domains of self-esteem may be more negatively affected by overweight/obese status than others $[1,7,8,11]$. Children with overweight/obesity seem to have an elevated risk of low self-esteem in the domains of sports, physical appearance and peer engagement in particular [1, 7]. Few studies based on large community samples have examined domain specific self-esteem in children with overweight, however.

A significant sub-group of overweight children demonstrates low self-esteem. Still, little is known about what characterises this group and whether weight and eating related factors could explain variation in self-esteem in children with overweight. To our knowledge no studies have examined this question in particular. Previous studies on general selfesteem among overweight children have, however, identified some factors which may be related to low self-esteem: eating habits and attitudes, peer bullying, parental evaluation of the child as heavy and degree of overweight [11-15]. In line with theories of self-esteem these factors are related to child ideals and emotional support from peers as well as to parental evaluation. We wanted to examine to which degree these above mentioned weightand eating-related factors could explain the variance in domain-specific self-esteem among overweight children as well as their relative importance.

Being the victim of bullying is found to be detrimental to self-esteem in normal-weight samples [16]. As children with overweight are more often stigmatised and victims of bullying than normal-weight children $[17,18]$, the experience of being bullied might thus be an important characteristic of the group of children with overweight reporting low self-esteem. Children with overweight experiencing bullying often describe the teasing to be weight- and appearance-related [19]. We would therefore hypothesise that bullying might be specifi- 
cally related to the self-esteem domains of physical appearance and athletic competence in overweight children. Likewise disturbed eating habits and attitudes are prevalent in overweight children [20] and in one study found to cluster with self-esteem in this group, but not in normal-weight children [21]. Thus, we wanted to examine if disturbed eating was related to low self-esteem scores in children with overweight. As issues regarding body size are central to disturbed eating and eating in general is a highly social behaviour, we hypothesise that disturbed eating is specifically related to evaluation of physical appearance and to social self-esteem in overweight children. Further older children, girls, children from families with lower socio-economic status (SES), a higher degree of overweight and who are evaluated by their parents to have weight problems are found to be more at risk for low selfesteem in overweight samples $[4,8,11,14,15,22-24]$. In previous studies these factors have mainly been examined one by one and not in larger models that could provide a clearer picture of their relative influence on self-esteem scores. In addition, the abovementioned factors have mainly been examined in terms of influence on global self-esteem. Some recent studies do, however, indicate that some of the predictors are differentially related to various domains of self-esteem $[11,12,22,24]$. These studies indicate that age, gender and parents' perception of the child's weight status are specifically related to the child's evaluation of physical appearance, while SES is more specifically related to athletic and social self-esteem. Most previous studies have, however, not been based on large general population samples, but mainly on relatively small or clinical samples.

Examining age, gender, SES, being the victim of bullying, parents' perception of weight status, disturbed eating and BMI in relation to different domains of self-esteem would provide a more detailed knowledge, beyond and above the knowledge base which has been established concerning global self-esteem. Potential findings might have clinical implications; for example, in the promotion of self-esteem in girls, issues related to physical appearance might be important to target, while for boys athletic competence could be a more relevant area. Another implication might be that in overweight children with low levels of satisfaction with their physical appearance one has to be especially observant in relation to symptoms of disturbed eating.

The aims of our study were to compare domain-specific self-esteem scores in overweight and normal-weight children and to identify factors that are related to low self-esteem in children with overweight/obesity. Factors were included in the model based on previous studies which indicate that these factors might have special relevance for self-esteem in overweight children. Associations were explored between age, gender, SES, being the victim of bullying, parents' perception of weight status, disturbed eating, BMI and domains of selfesteem in the group of children with overweight/obesity. More specifically, we examined the relative contribution of the above mentioned factors in relation to different self-esteem domains and how well the model could explain variation in the different self-esteem scores. No previous studies have examined all of these factors in one model, and few have used a domain-specific approach.

\section{Material and Methods}

\section{Sample}

Data stem from the second wave of The Bergen Child Study (BCS), a longitudinal, population-based study. In the first wave, which took place in 2002/2003, all primary school children from Bergen, aged 7-9 years $(N=9,430)$, their parents and their teachers were invited to participate in the study. 7,007 of the parents gave their informed consent to participation $[25,26]$. In the second wave 5,781 children (aged 11-13 years) and their parents participated; comprising 60\% of the original sample. The parents 
(one or both in co-operation) and the child completed questionnaires including measures of self-esteem (Self-Perception Profile for Children), disturbed eating (Eating Disturbance Scale-5), bullying, parents' evaluation of the child's weight status, parental education and SES as well as parent-reported height and weight of the child. The questionnaires were distributed to the families through the local schools and completed by the parents and children at home. The Eating Disturbance Scale- 5 and the Self-Perception Profile for Children were only included in the second wave of the BCS, not allowing for longitudinal analyses. The mean age of the sample was 11.8 years (SD $=0.8$ years), $48 \%$ were boys and $53 \%$ of the parents reported some level of university education. Data on BMI were available for 4,167 children. The group of children with missing data on height and weight had significantly lower SES, lower levels of satisfaction with their physical appearance and lower scholastic competence compared to the rest of the sample.

The data collection took place in the spring of 2006, and the study was approved by the Regional Committee for Medical Research Ethics in Western Norway and the Data Inspectorate in Norway.

\section{Instruments and Procedure}

\section{$B M I$}

The BMI of each child was calculated based on the child's parent-reported height and weight. The children were assigned to the different BMI categories based on the International Obesity Task Force's gender- and age-adjusted BMI criteria (isoBMI) [27]. The isoBMI cut-offs for overweight and obesity (isoBMI 25 and 30) are adjusted for age and gender and calculated to represent an equivalent to adult BMI 25 and 30. An isoBMI of 25 would therefore represent different and lower actual BMI values in children than in adults, varying with age and gender. Children with overweight and obesity were grouped together $(\mathrm{N}=545)$.

\section{Self-Esteem}

The Self-Perception Profile for Children (SPPC) [28] in a revised version, Self-Perception Profile for Adolescents - Revised (SPPA-R) [29], was used, including the sub-scales 'Scholastic Competence', 'Social Acceptance', 'Athletic Competence' and 'Physical Appearance'. The 'Global Self-Worth' and 'Behavioural Conduct' sub-scales were not included in the BCS questionnaire. Each sub-scale consists of six items, scored on a four-point scale (1-4). Mean domain scores $\leq 2$ were considered to indicate clinically low selfesteem in that area. The SPPC was developed for children aged 8-14 years, and it is widely used for research purposes. The internal reliability has been demonstrated to be high [30]. The SPPA-C used in the current study has been validated in a large sample of Norwegian adolescents and demonstrated high reliability [29]. Cronbach's alpha for the different sub-scales in this sample was 0.69 for Scholastic Competence, 0.76 for Social Acceptance, 0.75 for Athletic Competence and 0.83 for Physical Appearance.

SES

A proxy of SES was calculated based on parents' evaluation of their family's finances and the education level of both parents individually. Family finances were evaluated on a five-point scale ranging from very good to very poor. The educational level of each of the parents was also evaluated on a five-point scale. The scores from these three measures were converted into z-scores, and an overall mean expressing the SES of the family was subsequently calculated. Data from these measures of SES in the BCS are previously described in more detail, and significant relationships to mental health variables and income have been demonstrated [31].

\section{Bullying}

Bullying was measured by one item on the parent questionnaire, 'My child is being bullied by other children', and one item on the children's questionnaire, 'Other children are teasing or bullying me'. There was a moderate positive correlation between the child report and parent report on this measure, $r=0.51$, $\mathrm{p}<0.001$. The response categories for both parents and children were 'certainly true', 'somewhat true' or 'not true'. To be included in the group of children who were regarded as victims of bullying, the response to at least one of these items had to be 'certainly true' or 'somewhat true'. 
Parents' Evaluation of the Child's Weight Status

Parents' evaluation of the child's weight status was measured by one item, 'How do you evaluate your child's weight status?', with the following response categories: 'severely underweight', 'a little underweight', 'normal weight', 'a little overweight', and 'very overweight'. As such this measure is not necessarily related to the formal BMI categorisations but is used as an indication of the parents' subjective evaluation of their children's weight status.

\section{Disturbed Eating}

The Eating Disturbance Scale (EDS-5) [32] consists of five items. Examples of the type of questions used are: 'Are you satisfied with our eating habits?', 'Have you eaten to comfort yourself because you were unhappy?', 'Have you felt guilty about eating?', 'Have you felt that it was necessary for you to use a strict diet or other eating rituals to control your eating?' or 'Have you felt that you are too fat?'. Each item is scored on a four-point scale, with 0 indicating 'no problems' and 3 'high degree of problems', and the scores for each item are added together. The scale has demonstrated high internal consistency. Sensitivity and specificity for the scale with respect to DSM-IV eating disorders has been reported to be 0.90 and 0.88 , respectively [32]. In the present sample, Cronbach's alpha for EDS-5 was 0.73.

\section{Statistical Analysis}

Independent samples t-tests were used to investigate differences between the group consisting of normal-weight children $(n=3,622)$ and the group consisting of children with overweight/obesity ( $n=$ 545). Outcome variables were the SPPC-subscales and the EDS-5. Effect sizes for the differences were calculated using Cohens' $d$. An effect size of 0.2 is considered small, 0.5 medium and 0.8 is regarded as a large effect size. Pearson chi-square tests were used to calculate whether differences between the percentages of normal-weight children and children with overweight/obesity with self-esteem scores in the clinical range were significant.

In order to identify factors associated with low self-esteem in children with overweight/obesity, four multiple regression analyses were conducted in which gender, age, SES, EDS-5 scores, bullying, parents' evaluation of the child's weight status and BMI were entered as predictors. Dependent variables comprised the following self-esteem sub-scales: Scholastic Competence, Social Acceptance, Athletic Competence and Physical Appearance. Zero-order correlations of each predictor with the outcome variables were calculated, and the predictors that were significantly related to each self-esteem domain based on these analyses were included in the regression model for that specific domain. The selected predictors were entered together in the model. Preliminary analyses were conducted to ensure no violation of the assumptions of normality, linearity, and multi-collinearity.

\section{Results}

\section{Sample Characteristics}

In this sample, $86.9 \%$ of the children were of normal weight $(\mathrm{N}=3,622), 11.1 \%$ were overweight $(\mathrm{N}=464)$ and $1.9 \%$ suffered from obesity $(\mathrm{N}=81)$ according to the weight status criteria of Cole et al. [27]. Among the families of normal-weight children, 46.2\% had SES below average, compared with $65.2 \%$ of the families of children with overweight/obesity. In all, $14.0 \%$ of the normal-weight children reported being victims of bullying, compared with $30.7 \%$ of the children with overweight/obesity.

\section{Self-Esteem and Disturbed Eating}

The independent sample t-tests revealed statistically significant differences between children with overweight/obesity and normal-weight children on all SPPC sub-scales as well as on the EDS-5. All differences indicated more problems among the group of children with overweight/obesity. The mean scores for the self-esteem measures and the EDS-5 for the 


\begin{tabular}{l|l}
\hline Obes Facts 2012;5:722-733 \\
\hline DOI: 10.1159/000338333 \\
Published online: October 23, 2012 & $\begin{array}{l}\text { C 2012 S. Karger GmbH, Freiburg } \\
\text { www.karger.com/ofa }\end{array}$ \\
\hline
\end{tabular}

Danielsen et al.: Factors Associated with Low Self-Esteem in Children with Overweight

Table 1. Mean scores (95\% confidence intervals) for EDS-5 and SPPC in children with and without overweight/obesity

\begin{tabular}{lllll}
\hline Characteristics & Normal weight & Overweight/obesity & Effect size $^{\mathrm{a}}$ & $p$ value \\
\hline $\mathrm{N}$ & 3622 & 545 & & \\
\hline $\begin{array}{l}\text { EDS-5 } \\
\quad \text { Total score }\end{array}$ & $1.62(1.55-1.69)$ & $3.82(3.54-4.09)$ & -0.81 & $<0.001$ \\
\hline SPPC & & & & \\
$\quad$ Scholastic & $3.08(3.06-3.09)$ & $2.89(2.85-2.94)$ & 0.36 & $<0.001$ \\
$\quad$ Social & $3.29(3.27-3.30)$ & $3.02(2.97-3.07)$ & 0.47 & $<0.001$ \\
$\quad$ Athletic & $2.94(2.92-2.96)$ & $2.59(2.53-2.64)$ & 0.59 & $<0.001$ \\
$\quad$ Appearance & $3.29(3.27-3.31)$ & $2.83(2.76-2.89)$ & 0.68 & $<0.001$ \\
\hline
\end{tabular}

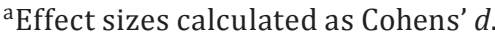

Table 2. Percentage of children with normal weight and overweight/obesity with self-esteem scores in the clinical range

\begin{tabular}{llll}
\hline & Normal weight & Overweight/obesity & Chi-square $^{\mathrm{a}}$ \\
\hline Low Scholastic Competence scores & $3.1 \%$ & $7.8 \%$ & $23.58^{* * *}$ \\
Low Social Acceptance scores & $3.0 \%$ & $8.0 \%$ & $30.17^{* * * *}$ \\
Low Athletic Competence scores & $8.1 \%$ & $20.9 \%$ & $79.20^{* * *}$ \\
Low Physical Appearance scores & $4.9 \%$ & $16.5 \%$ & $101.57^{* * *}$ \\
\hline
\end{tabular}

${ }^{* * *} \mathrm{p}<0.001$.

${ }^{\mathrm{a} C}$ Continuity corrected values.

normal-weight children and for the children with overweight/obesity as well as the significance levels and effect sizes for the group differences are presented in table 1.

Table 2 presents the percentage of children with normal weight and overweight/obesity that report a clinically significant low self-esteem (mean domain scores $\leq 2$ ). Significantly more children with overweight/obesity reported having experienced bullying $\left(\chi^{2}=93.09\right.$, $\mathrm{p}<0.001)$.

\section{Factors Associated with Low Domain-Specific Self-Esteem in Children with Overweight/} Obesity

Table 3 shows the results of the multiple regression analyses for the four different selfesteem domains. In relation to Scholastic Competence, the total variance explained by the model as a whole was $14.9 \%, F(4,443)=19.45, \mathrm{p}<0.001$. In this model factors significantly associated with low Scholastic Competence were: lower SES, a high score on the EDS-5 and being bullied.

For Social Acceptance the total variance explained by the model was $28.7 \% \mathrm{~F}(4,498)=$ $50.21, \mathrm{p}<0.001$. Low Social Acceptance was significantly related to a high score on the EDS-5 and being bullied.

For Athletic Competence the model explained $20.4 \%$ of the variance, $F(6,435)=18.55$, $\mathrm{p}<0.001$. Low Athletic Competence self-esteem in this model was significantly associated with a low SES, high EDS-5 score and being bullied. 
Table 3. Regression analyses of factors related to self-esteem scores in children with overweight

\begin{tabular}{|c|c|c|c|c|}
\hline Predictors & B & SEB & $B$ & R-square \\
\hline \multicolumn{4}{|l|}{ Scholastic Competence } & 0.149 \\
\hline SES (z-scores) & 0.084 & 0.032 & $0.116^{* *}$ & \\
\hline EDS-5 & -0.029 & 0.008 & $-0.173^{* *}$ & \\
\hline Bullied $(0=$ no, $1=$ yes $)$ & -0.294 & 0.053 & $-0.253^{* *}$ & \\
\hline BMI & -0.011 & 0.008 & -0.061 & \\
\hline \multicolumn{4}{|l|}{ Social Acceptance } & 0.287 \\
\hline EDS-5 & -0.051 & 0.008 & $-0.281^{* *}$ & \\
\hline Bullied $(0=$ no, $1=$ yes $)$ & -0.469 & 0.050 & $-0.367^{* *}$ & \\
\hline Parents' evaluation of weight (1-5) & -0.018 & 0.042 & -0.018 & \\
\hline BMI & -0.008 & 0.008 & -0.038 & \\
\hline \multicolumn{4}{|l|}{ Athletic Competence } & 0.204 \\
\hline Gender (boys $=1$, girls $=2$ ) & -0.089 & 0.054 & -0.073 & \\
\hline SES (z-scores) & 0.078 & 0.036 & $0.094^{*}$ & \\
\hline EDS-5 & -0.053 & 0.009 & $-0.281^{* *}$ & \\
\hline Bullied $(0=$ no, $1=$ yes $)$ & -0.256 & 0.060 & $-0.194^{* *}$ & \\
\hline Parents' evaluation of weight (1-5) & -0.041 & 0.049 & -0.039 & \\
\hline BMI & -0.018 & 0.010 & -0.085 & \\
\hline \multicolumn{4}{|l|}{ Physical Appearance } & 0.485 \\
\hline Gender $($ boys $=1$, girls $=2$ ) & -0.138 & 0.050 & $-0.161^{* *}$ & \\
\hline Age & -0.154 & 0.032 & $-0.160^{* *}$ & \\
\hline EDS-5 & -0.135 & 0.009 & $-0.580^{* *}$ & \\
\hline Bullied ( $0=$ no, $1=$ yes $)$ & -0.118 & 0.056 & $-0.073^{*}$ & \\
\hline Parents' evaluation of weight (1-5) & -0.096 & 0.046 & $-0.074^{*}$ & \\
\hline BMI & -0.019 & 0.009 & $-0.073^{*}$ & \\
\hline \multicolumn{5}{|l|}{${ }^{*} \mathrm{p}<0.05$} \\
\hline
\end{tabular}

For Physical Appearance the model explained a total of $48.5 \%$ of the variance, $F(6,493)$ $=77.38, \mathrm{p}<0.001$. Low scores on the Physical Appearance sub-scale were significantly related to gender (being female), older age, a high EDS-5 score, being bullied, higher BMI and parents' evaluation of weight status as heavy.

\section{Discussion}

In this population-based sample, children with overweight demonstrated significantly lower self-esteem than normal-weight children on all domain-specific areas. For children with overweight and obesity the self-esteem domains of Athletic Competence and Physical Appearance were most impaired, according to the effect sizes. Although only a sub-sample of children reported clinically low self-esteem, prevalence of self-esteem scores in the clinical range were more than double among the overweight children compared to the normal-weight children.

In the sample of children with overweight, disturbed eating and being the victim of bullying were significantly related to low scores in all of the four domains of self-esteem. Being female, older, having a higher BMI and evaluated by parents' to be overweight were associated with a negative attitude to physical appearance in overweight children. The 
model was most explanatory in relation to Physical Appearance and Social Competence, where it contributed to $48.5 \%$ and $28.7 \%$ of the variance of scores, respectively.

The finding that evaluation of Physical Appearance and Athletic Competence were most negatively affected in children with overweight/obesity is in line with some previous studies $[4,7]$. Since overweight and obesity are conditions that are directly linked to appearance and the capability to move the body, these results are not surprising. A tendency to evaluate Physical Appearance more negatively among children with overweight might be related to the massive media focus in our society on slimness as a body ideal. Concerning lower Athletic Competence we might speculate that this in general is related to physical fitness and the physical ability to succeed in sports being impaired in overweight children. In Norway physical activity for the age group in question is often dominated by participation in competitive sports, rather than play or exercise. This might represent an obstacle for overweight children in finding enjoyable arenas for physical activity. A clinical implication might be that finding settings and activities that allow overweight children to enjoy and master physical activity seems important, not only in relation to improving physical fitness but for enhancing their self-perception as well.

One of the most interesting findings from the present study is that disturbed eating was significantly related to low scores on all four self-esteem domains in children with overweight/obesity; therefore disturbed eating seems to be a central factor related to low selfesteem in this group. In some studies of normal-weight children, low self-esteem is found to be related to risk of developing disturbed eating patterns and attitudes [33]. We could speculate that this might be the case in overweight children as well, but the cross-sectional nature of our data does not allow us to draw inferences about directionality of influence. Another study demonstrated that global self-worth clusters with body image and eating disorder symptoms in children with overweight, but not in normal-weight children [21], indicating that, in children with overweight, self-esteem could be more closely linked to issues regarding eating, body weight and shape. This is in line with our finding that disturbed eating is a pronounced factor related to low self-esteem across all domains in children with overweight/obesity, even when controlling for other relevant factors. Disturbed eating habits and negative emotions in relation to eating thus seem especially important in relation to the psychological adjustment of children with overweight. For overweight children presenting for treatment, disturbed eating habits and attitudes seem important to assess and target along with self-esteem. While a fear might be that attempts to lose weight influence eating pathology negatively, most studies reporting on the effect of standardised behavioural weight loss treatments on eating pathology depicted minimal risks for development of eating disorders [34, 35].

In our study, experiencing bullying was significantly related to low scores in all selfesteem domains in children with overweight/obesity. Thus bullying contributes significantly to explaining the variation in self-esteem in this sample. Few studies have examined the relationship between bullying and self-esteem in children with overweight/obesity [4], but a relationship between bullying and a negative evaluation of Physical Appearance has been demonstrated $[11,12]$. In our study, however, bullying was more strongly related to the other domains of self-esteem. One possible explanation for this is that, when entered together with other variables in a regression model, some of the factors other than bullying may have more explanatory power specifically in relation to Physical Appearance.

Many studies, however, have demonstrated that children with overweight are more often victims of bullying than normal-weight children $[17,18]$, and in one study low selfesteem is found to mediate the association between overweight/obese status and being bullied [12]. Being the victim of bullying seems to be related to low self-esteem in children with overweight/obesity, as is the case with normal-weight children [16]. We could spec- 
ulate that the fact that children with overweight/obesity are more often victims of bullying could put them at greater risk of developing problems with their self-esteem. Longitudinal studies are, however, needed to examine causality between low self-esteem and bullying.

In the present study girls and older children more often had a negative evaluation of their Physical Appearance. One explanation why overweight/obesity could be less detrimental to boys' evaluation of their physical appearance is the presence of different bodily ideals for boys and girls [36]. Age in the current study was negatively related to Physical Appearance scores. It does seem reasonable that Physical Appearance becomes increasingly important when children mature parallel to their growing awareness of romantic relationships. It is also possible that older children are more aware of their bodies due to changes secondary to puberty. Other studies have indicated that age and gender could moderate the effect of overweight/obesity on various aspects of self-esteem $[4,15]$. The relatively weak relationship between age and domains of self-esteem found in the present study could therefore partly be attributable to the limited age range of our sample.

In our model, low SES was significantly related to low Scholastic Competence and low Athletic Competence in overweight children. The SES measure in this study is partly based on parental education level, which in general is found to be related to child school performance [37]. Hence it is not surprising that SES is associated with evaluation of Scholastic Competence. Likewise, family SES is related to the amount of physical activity in children [38] which most likely would influence evaluation of Athletic Competence. This link might be particularly strong for overweight children due to the higher prevalence of overweight in lower SES samples in developed countries [39].

In this study, parents' evaluation of the child's weight status as being above average was significantly related only to Physical Appearance scores. Only a few other studies have addressed the relationship between parents' evaluations of a child's weight and self-esteem $[11,14]$. Young-Hyman et al. [11] reported that parental perception of the child as heavier than average was linked to low appearance self-esteem in the child. Davison and Birch [14] concluded that parents' attitudes to a child's weight could represent an additional burden on the child's self-esteem. All in all, parents' evaluation of a child's weight status as being heavier than average does not seem to be an important predictor of low self-esteem in children with overweight/obesity in general, but to be specifically related to evaluation of Physical Appearance. This finding might partly reflect critical comments about weight and body size made by parents, which could be an area for further research.

Degree of overweight was only significantly associated with evaluation of Physical Appearance in our model. Some studies find that, among children with overweight/obesity, the persons with the highest BMI values are most likely to have lower self-esteem $[8,23]$. Young-Hyman et al. [11], on the other hand, found that severity of obesity was not related to self-esteem. One explanation might be a threshold effect in the relationship between BMI and self-esteem, suggesting that further increases in BMI above the threshold do not influence self-esteem. Other studies [23] highlight that the self-perceived degree of overweight might be a better predictor of low self-esteem than actual weight. Our study likewise indicates that factors other than higher BMI are more strongly related to low self-esteem.

One strength of the present study is the use of a large population-based sample, fostering the generalisability of the results. Domain-specific self-esteem has so far been understudied in this age group. While some previous studies have identified individual weight- and eatingrelated factors affecting self-esteem in overweight children, the present study is taking a broader perspective, examining these factors together to see how well they can account for variations in self-esteem scores within overweight children.

A number of limitations of the present study should be kept in mind. As this is a crosssectional study, it does not allow us to draw any inferences about causality. Another limi- 
tation of the present study is the use of parent-reported measures of BMI and the relatively high percentage of missing data on BMI scores. Several studies showed that self-reported and parent-reported height and weight could be biased in terms of underreporting of weight, especially among adolescents and children who are heavy [40-42]. This might be attributable to factors such as not actually knowing the child's weight/height and to other psychological factors related to the evaluation of body weight and shape, or to social desirability. In the present study, parents completed the questionnaire at home, which could enable the actual weight of the children to be monitored and thereby make it a relatively more accurate measure of this variable. Drop-out analyses on children with missing values on height or weight revealed that this group of children had lower SES and more self-esteem problems than the group that participated/answered. It is probable that some of the children in the former group were overweight. Another prevalence study on overweight from Bergen using objective height and weight measures from the same age group as the present study, however, found similar prevalence rates for overweight including obesity (13.8\%) [43].

The use of self-report measures is also a weakness, and some of the questions regarding SES and bullying has not been validated in other studies than in the BCS. Likewise, the internal consistency for the Scholastic Competence Scale was sub-optimal in the present sample.

Predictors for variance in self-esteem scores in overweight children in the present study were selected with background in theory and in previous studies indicating that they might be of special relevance to this group. Being part of a larger study, however, information about some relevant predictors, such as family functioning, was not available. Clinical implications from our study may be that in interventions for overweight/obesity themes related to appearance may seem more relevant for self-esteem in girls and older children. As disturbed eating was related to all domains of self-esteem, it might be an especially important target in promoting self-esteem in children with overweight/obesity. More studies are needed to clarify the relationship between disturbed eating and psychological maladjustment in overweight children, as symptoms of these conditions seems to be closely associated. While the present study reports on distribution of self-esteem scores over different domains in overweight children, future research needs to clarify which self-esteem domains are considered particularly important for more global evaluations of self-worth in this group. For future research, self-esteem could also be an important outcome measure in treatment studies in relation to childhood obesity in addition to measures of adiposity.

\section{Acknowledgements}

We thank the Bergen Child Study (BCS) research group and, in particular, Astri Lundervold and Einar Heiervang, who form the management group, together with Kjell Morten Stormark, for the collection of the data. The BCS was supported financially by the Norwegian Directorate for Health, the Research Council of Norway, Western Norway Regional Health Authority, the Meltzer legacy and the City of Bergen.

\section{Disclosure Statement}

There are no conflicts of interest. 
Danielsen et al.: Factors Associated with Low Self-Esteem in Children with Overweight

\section{References}

- 1 Franklin J, Denyer G, Steinbeck KS, Caterson ID, Hill AJ: Obesity and risk of low self-esteem: a statewide survey of Australian children. Pediatrics 2006;118:2481-2487.

- 2 Pesa JA, Syre TR, Jones E: Psychosocial differences associated with body weight among female adolescents: the importance of body image. J Adolesc Health 2000;26:330-337.

- 3 Strauss RS: Childhood obesity and self-esteem. Pediatrics 2000;105:e15.

$\checkmark 4$ Wardle J, Cooke L: The impact of obesity on psychological well-being. Best Pract Res Clin Endocrinol Metab 2005;19:421-440.

- 5 Friedman AM, Brownell, KD: Psychological correlates of obesity: moving to the next research generation. Psychol Bull 1991;117:3-20.

6 Zametkin AJ, Zoon CK, Klein HW, Munson S: Psychiatric aspects of child and adolescent obesity: a review of the past 10 years. J Am Acad Child Adolesc Psychiatry 2004;43:134-150.

7 Griffiths LJ, Parsons TJ, Hill AJ: Self-esteem and quality of life in obese children and adolescents: a systematic review. Int J Pediatr Obes 2010;5:282-304.

8 Israel AC, Ivanova MY: Global and dimensional self-esteem in preadolescent and early adolescent children who are overweight: age and gender differences. Int J Eat Disord 2002;31:424-429.

9 Harter S, Whitesell, NR: The importance of importance ratings in understanding adolescents' self-esteem: Beyond statistical parsimony; in Riding R (ed): Self-Perception. Westport, Greenwood Press, 2001, pp 3-25.

10 Rosenberg M, Schooler, C, Schoenbach, C, Rosenberg, F: Global self-esteem and spesific self-esteem: different concepts, different outcomes. Am Sociol Rev 1995;60:141-156.

11 Young-Hyman D, Schlundt DG, Herman-Wenderoth L, Bozylinski K: Obesity, appearance, and psychosocial adaptation in young African American children. J Pediatr Psychol 2003;28:463-472.

12 Fox CL, Farrow CV: Global and physical self-esteem and body dissatisfaction as mediators of the relationship between weight status and being a victim of bullying. J Adolesc 2009;32:1287-1301.

$\checkmark 13$ Gusella J, Goodwin J, van Roosmalen E: 'I want to lose weight': early risk for disordered eating? Paediatr Child Health 2008;13:105-110.

14 Davison KK, Birch LL: Weight status, parent reaction, and self-concept in five-year-old girls. Pediatrics 2001;107:46-53.

15 Erickson SJ, Hahn-Smith A, Smith JE: One step closer: understanding the complex relationship between weight and self-esteem in ethnically diverse preadolescent girls. J Appl Dev Psychol 2009;30:129-139.

16 Hawker DSJ, Boulton MJ: Twenty years' research on peer victimization and psychosocial maladjustment: A meta-analytic review of cross-sectional studies. J Child Psychol Psychiatry 2000;41:441-455.

17 Falkner NH, Neumark-Sztainer D, Story M, Jeffery RW, Beuhring T, Resnick MD: Social, educational, and psychological correlates of weight status in adolescents. Obes Res 2001;9:32-42.

18 Storch EA, Ledley DR: Peer victimization and psychosocial adjustment in children: current knowledge and future directions. Clin Pediatr (Phila) 2005;44:29-38.

19 Eisenberg ME, Neumark-Sztainer D, Haines J, Wall M: Weight-teasing and emotional well-being in adolescents: longitudinal findings from project eat. J Adolesc Health 2006;38:675-683.

20 Braet C, Claus L, Goossens L, Moens E, Van Vlierberghe L, Soetens B: Differences in eating style between overweight and normal-weight youngsters. J Health Psychol 2008;13:733-743.

21 Gibson LY, Byrne SM, Blair E, Davis EA, Jacoby P, Zubrick SR: Clustering of psychosocial symptoms in overweight children. Aust N Z J Psychiatry 2008;42:118-125.

22 McCullough N, Muldoon O, Dempster M: Self-perception in overweight and obese children: a cross-sectional study. Child Care Health Dev 2009;35:357-364.

23 Miller CT, Downey KT: A meta-analysis of heavy-weight and self-esteem. J Pers Soc Psychol Rev 1999;3: 68-84.

24 O’Dea JA: Self-concept, self-esteem and body weight in adolescent females - a three-year longitudinal study. J Health Psychol 2006;11:599-611.

-25 Heiervang E, Stormark KM, Lundervold AJ, Heimann M, Goodman R, Posserud MB, Ullebo AK, Plessen KJ, Bjelland I, Lie SA, Gillberg C: Psychiatric disorders in Norwegian 8-to 10-year-olds: an epidemiological survey of prevalence, risk factors, and service use. J Am Acad Child Adolesc Psychiatry 2007;46:438-447.

-26 Stormark KM, Heiervang E, Heimann M, Lundervold A, Gillberg C: Predicting nonresponse bias from teacher ratings of mental health problems in primary school children. J Abnorm Child Psychol 2008;36: 411-419.

27 Cole T, Bellizzi MC, Flegal KM, Dietz WH: Establishing a standard definition for child overweight and obesity worldwide: international survey. BMJ 2000;320:1240-1243.

28 Harter S: Manual for the Self-Perception Profile for Children. Denver, University of Denver, 1985.

29 Wichstrøm L: Harters' Self-Perception Profile for Adolescents: reliability, validity and evaluation of the question format. J Pers Assess 1995;65:100-116.

30 Muris P, Meesters C, Fijen P: The self-perception profile for children: further evidence for its factor structure, reliability, and validity. Person Ind Diff 2003;35:1791-1802.

-31 Bøe T, Øverland S, Lundervold A J, Hysing M: Socioeconomic status and children's mental health: results from the Bergen Child Study. Soc Psychiatry Psychiatr Epidemiol 2012;47:1557-1566. 
-32 Rosenvinge JH, Perry JA, Bjorgum L, Bergersen TD, Silvera DH, Holte A: A new instrument measuring disturbed eating patterns in community populations: development and initial validation of a five-item scale (eds-5). Eur Eat Disord Rev 2001;9:123-132.

33 Shea ME, Pritchard ME : Is self-esteem the primary predictor of disordered eating? Person Ind Diff 2007; 42:1527-1537.

-34 Butryn ML, Wadden TA: Treatment of overweight in children and adolescents: does dieting increase the risk of eating disorders? Int Eat Disord 2005;37:285-293.

35 Goossens L, Braet C, Verbeken S, Decaluwe V, Bosmans G: Long-term outcome of pediatric eating pathology and predictors for the onset of loss of control over eating following weight-loss treatment. Int J Eat Disord 2011;44:397-405.

-36 Pierce JW, Wardle J: Self-esteem, parental appraisal and body-size in children. J Child Psychol Psychiatry 1993;34:1125-1136.

-37 Davis-Kean PE: The influence of parent education and family income on child achievement: the indirect role of parental expectations and the home environment. J Fam Psychol 2005;19:294-304.

-38 La Torre G, Masala D, De Vito E, Langiano E, Capelli G, Ricciardi W; Physical Activity and Socio-Economic Status collaborative group: Extra-curricular physical activity and socioeconomic status in Italian adolescents. BMC Public Health 2006;6:22.

-39 Wang YF: Cross-national comparison of childhood obesity: the epidemic and the relationship between obesity and socioeconomic status. Int J Epidemiol 2001;30:1129-1136.

40 Brener ND, McManus T, Galuska DA, Lowry R, Wechsler H: Reliability and validity of self-reported height and weight among high school students. J Adolesc Health 2003;32:281-287.

$\checkmark 41$ O'Connor DP, Gugenheim JJ: Comparison of measured and parents' reported height and weight in children and adolescents. Obesity 2011;19:1040-1046.

-42 Tokmakidis SP, Christodoulos AD, Mantzouranis NI: Validity of self-reported anthropometric values used to assess body mass index and estimate obesity in Greek school children. J Adolesc Health 2007;40:305310.

43 Juliusson PB, Eide GE, Roelants M, Waaler PE, Hauspie R, Bjerknes R: Overweight and obesity in Norwegian children: prevalence and socio-demographic risk factors. Acta Paediatr 2010;99:900-905. 